\title{
Oxidation-Induced Whisker Growth on the Surface of Sn-6.6(La, Ce) Alloy
}

\author{
TUNG-HAN CHUANG, ${ }^{1,2}$ HSIU-JEN LIN, ${ }^{1}$ and CHIH-CHIEN CHI ${ }^{1}$ \\ 1.--Institute of Materials Science and Engineering, National Taiwan University, Taipei 106, \\ Taiwan. 2.—e-mail: tunghan@ntu.edu.tw
}

During solidification of rare-earth (RE)-containing Sn-6.6(La, Ce) alloys, $\left(\mathrm{La}_{0.93} \mathrm{Ce}_{0.07}\right) \mathrm{Sn}_{3}$ intermetallic clusters form in the near $\beta$-Sn matrix. These $\left(\mathrm{La}_{0.93} \mathrm{Ce}_{0.07}\right) \mathrm{Sn}_{3}$ intermetallics oxidize predominately after air storage at room temperature for short time periods. Accompanying the oxidation reaction, tin sprouts appear on the outer surface of the intermetallic clusters. Increasing the storage time at room temperature leads to the formation of thread-like tin whiskers. In specimens stored at $150^{\circ} \mathrm{C}$ in an air furnace, only a small amount of tin sprouts can be found in the interior regions of the oxidized $\left(\mathrm{La}_{0.93} \mathrm{Ce}_{0.07}\right) \mathrm{Sn}_{3}$ intermetallics. However, many coarse tin hillocks formed around the intermetallic clusters. The driving force for whisker growth is the compressive stress induced by the volume expansion of $\left(\mathrm{La}_{0.93}\right.$ $\left.\mathrm{Ce}_{0.07}\right) \mathrm{Sn}_{3}$, which extrudes the tin atoms released by the oxidation reaction of these RE intermetallics. In addition, the huge compressive stress accumulated by the volume expansion of the drastically oxidized $\mathrm{RE}$ intermetallics during $150^{\circ} \mathrm{C}$ air storage extrudes the $\mathrm{Sn}-6.6(\mathrm{La}, \mathrm{Ce})$ matrix around the $\mathrm{RE}$ oxides to form the coarse hillocks.

Key words: Rare-earth elements, oxidation, tin whiskers, hillocks

\section{INTRODUCTION}

As rare-earth (RE) elements are highly chemically active, they have been widely used in order to refine microstructures and improve mechanical properties in the steel, Al-alloy, and Mg-alloy industries. ${ }^{1}$ Another application is in bonding of nonwettable materials, such as ceramics, glass, graphite, aluminum, and titanium. ${ }^{2}$ Recently, rareearth elements have also been added to solders to improve their physical and mechanical properties. The beneficial effects of the addition of mixed metal (Ce, La) into Sn-9Zn, ${ }^{3} \mathrm{Sn}-3.5 \mathrm{Ag},{ }^{4} \mathrm{Sn}-0.7 \mathrm{Cu},{ }^{5}$ and $\mathrm{Sn}-3 \mathrm{Ag}-0.5 \mathrm{Cu}^{6}$ alloys on melting temperature, wettability, tensile strength, and creep resistance have been proved. Recently, Dudek et al. reported that a Sn-3.9Ag- $0.7 \mathrm{Cu}$ solder doped with $0.1 \mathrm{wt} \%$ and 0.5 wt.\% La exhibited much higher ductility than the undoped alloy, which indicated that the addition

(Received April 18, 2007; accepted July 2, 2007;

published online September 21, 2007) of rare-earth elements into solder could improve the mechanical shock resistance of electronic packages and lead to increased reliability in portable devices. ${ }^{7,8}$

However, an amazingly rapid growth of tin whiskers has been observed in a rare-earth-doped $\mathrm{Sn}-3 \mathrm{Ag}-0.5 \mathrm{Cu}-0.5 \mathrm{Ce}$ solder-ball grid array (BGA) package. It is known that tin whiskers can cause short circuits in solder joints and result in the failure of electronic devices. The addition of rare-earth elements in the pursuit of $\mathrm{Pb}$-free solders might degrade the reliability of electronic products. ${ }^{9}$ In another study, whisker growth even occurred in a Sn-3Ag-0.5Cu doped with 0.1 wt.\% Ce. ${ }^{10}$ It is evidenced that the appearance of tin whiskers in these alloys is attributed to the predominate oxidation of rare-earth intermetallic clusters during storage in air. In order to further clarify the correlation of whisker growth with the rare-earth intermetallics, binary Sn-RE alloys with higher RE contents have been investigated, as they provide a large amount of intermetallic clusters in the alloy matrix. In addition, since rare-earth mixed metals containing both 
La and Ce costs less than pure rare-earth elements and is the most popularly used metal in industry for material modifications, whisker growth in a Sn-6.6 (La, Ce) has been investigated.

\section{EXPERIMENTAL}

The rare-earth mixed metal used in this study contained $12 \% \mathrm{Ce}, 2 \% \mathrm{Pr}, 0.3 \% \mathrm{Nd}$, and $85.7 \% \mathrm{La}$ (wt.\%). For the preparation of $\mathrm{Sn}-6.6(\mathrm{La}, \mathrm{Ce})$ alloy, the mixed metal was added to pure $\mathrm{Sn}$, and the mixture was melted at $1,000^{\circ} \mathrm{C}$ under a vacuum of $10^{-4} \mathrm{~Pa}$. After solidification, the ingots were cut with a diamond saw, ground with 2000 grit $\mathrm{SiC}$ paper, and polished with $0.3 \mu \mathrm{m} \mathrm{Al}_{2} \mathrm{O}_{3}$ powder. After storage at room temperature and $150^{\circ} \mathrm{C}$ for various time periods, the microstructures of the specimens and the morphology of the tin whiskers that had formed on the surface were observed by scanning electron microscopy (SEM), and their chemical compositions were analyzed by an electron probe microanalyzer (EPMA). To determine the oxidation behaviors of these alloys, the percentage weight gain (weight gain/original weight $\times 100 \%$ ) of the specimens was continuously measured at $150^{\circ} \mathrm{C}$ in an air furnace using a thermal gravity analyzer (TGA). In addition, the percentage weight gain of the specimens during air storage at room temperature was measured intermittently with a microbalance.

\section{RESULTS AND DISCUSSION}

The microstructure of as-cast $\mathrm{Sn}-6.6(\mathrm{La}, \mathrm{Ce})$ alloy contains many clusters with a size of about $10 \mu \mathrm{m}$, as shown in Fig. 1. EPMA analyses indicate that the chemical compositions (at.\%) of these clusters are Sn:La:Ce = 71.9:26.1:2.0, which correspond to the $\left(\mathrm{La}_{0.93} \mathrm{Ce}_{0.07}\right) \mathrm{Sn}_{3}$ phase. No sign of $\mathrm{Pr}$ and $\mathrm{Nd}$ can be detected in the intermetallic clusters due to their minor concentrations in the alloy. According to the binary La-Sn phase diagram, these $\left(\mathrm{La}_{0.93} \mathrm{Ce}_{0.07}\right) \mathrm{Sn}_{3}$ clusters resulted from a peritectic reaction during solidification of the Sn-6.6La alloy. ${ }^{11}$ The matrix of this alloy should consist of $\beta$-Sn mixed with a small amount of the eutectic (La, Ce) $\mathrm{Sn}_{3}$ phase. Figure 2 reveals that, after storage at room temperature in air for $0.5 \mathrm{~h}$, the surface of the $\left(\mathrm{La}_{0.93} \mathrm{Ce}_{0.07}\right) \mathrm{Sn}_{3}$ intermetallic phase oxidized to a composition of Sn:La:Ce:O = 36.5:17.2:2.1:44.2 (at.\%). Accompanying the oxidation of these intermetallic clusters, bright particles with a composition near pure tin appeared on the surfaces of certain intermetallics. The diameters of these tin sprouts were about $1 \mu \mathrm{m}$. As the storage time increased, greater numbers of rare-earth intermetallic clusters exhibited the formation of tin sprouts on their surfaces. In addition, certain tin sprouts were found to grow slightly longer after the initial formation, as shown in Fig. 2c. After long-term storage at room temperature, all of the $\left(\mathrm{La}_{0.93} \mathrm{Ce}_{0.07}\right) \mathrm{Sn}_{3}$ intermetallics were covered with tin sprouts with lengths of about
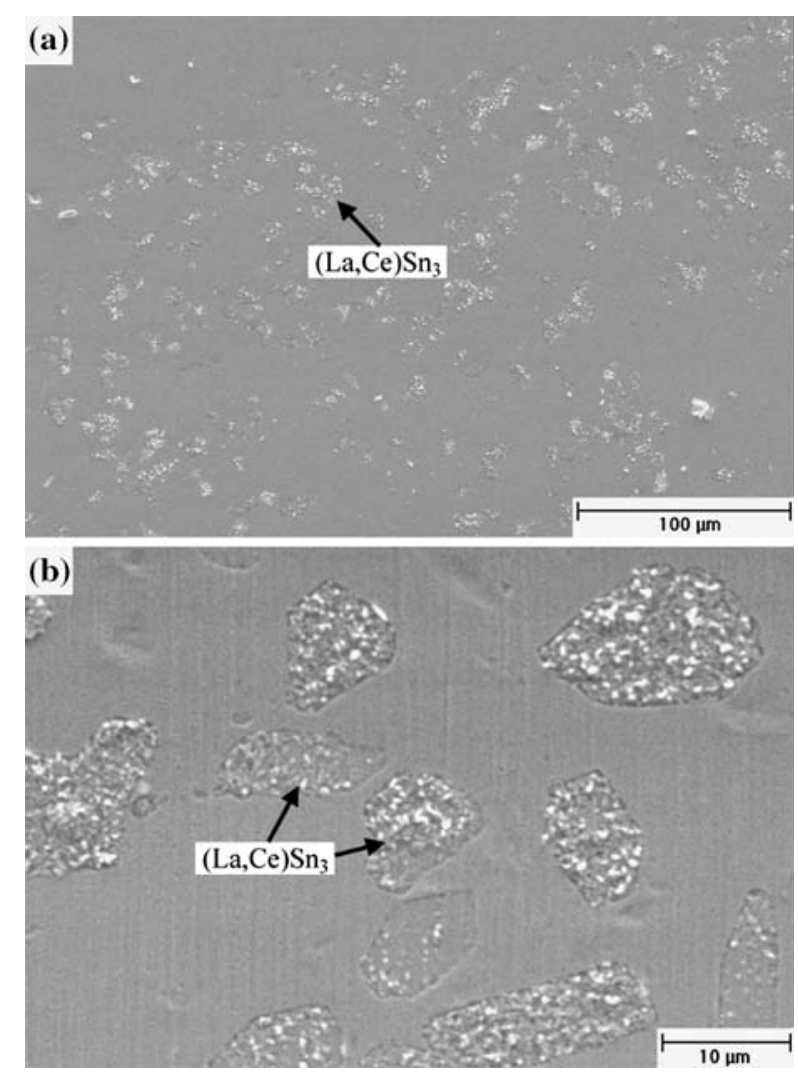

Fig. 1. Microstructure of the as-cast Sn-6.6(La, Ce) alloy, showing peritectic $\left(\mathrm{La}_{0.93} \mathrm{Ce}_{0.7}\right) \mathrm{Sn} 3$ intermetallic clusters in the near $\beta$-Sn matrix: (a) low magnification, (b) high magnification.

$3.0 \mu \mathrm{m}$, as illustrated in Fig. 3. However, in a rare case, shown in Fig. $3 \mathrm{~b}$, a long whisker grew to a length of over $40 \mu \mathrm{m}$ after air storage at room temperature for $188 \mathrm{~h}$. During the period of storage from $188 \mathrm{~h}$ to $559 \mathrm{~h}$, the morphology of the tin whiskers on the surface of the $\left(\mathrm{La}_{0.93} \mathrm{Ce}_{0.07}\right) \mathrm{Sn}_{3}$ intermetallic clusters remained unchanged (Fig. 3c). This implies that the driving force for whisker growth had been exhausted. From Fig. 3, it can also be observed that pressure has been applied to the $\mathrm{Sn}-6.6(\mathrm{La}, \mathrm{Ce})$ matrix adjacent to the rare-earth intermetallic clusters and caused a convex profile. This indicates that the $\left(\mathrm{La}_{0.93} \mathrm{Ce}_{0.07}\right) \mathrm{Sn}_{3}$ intermetallics expanded in volume and that this expansion was constrained by the near $\beta$-Sn matrix.

During air storage at an elevated temperature of $150^{\circ} \mathrm{C}$, the small tin sprouts in the interior regions of the $\left(\mathrm{La}_{0.93} \mathrm{Ce}_{0.07}\right) \mathrm{Sn}_{3}$ intermetallic phase grew very slowly, as shown in Fig. 4 . In contrast, many coarse hillocks appeared at the edges of the intermetallic clusters at the early stage of $150^{\circ} \mathrm{C}$ storage for 10 min (Fig. 4a). These hillocks grew obviously when the storage time was increased from 10 to 90 min, as illustrated in Fig. 4. These hillocks were about $7 \mu \mathrm{m}$ in size after storage at $150^{\circ} \mathrm{C}$ for $40 \mathrm{~h}$, as shown in Fig. 5a. However, these tin hillocks ceased to grow during long-term storage from $40 \mathrm{~h}$ to $224 \mathrm{~h}$ 

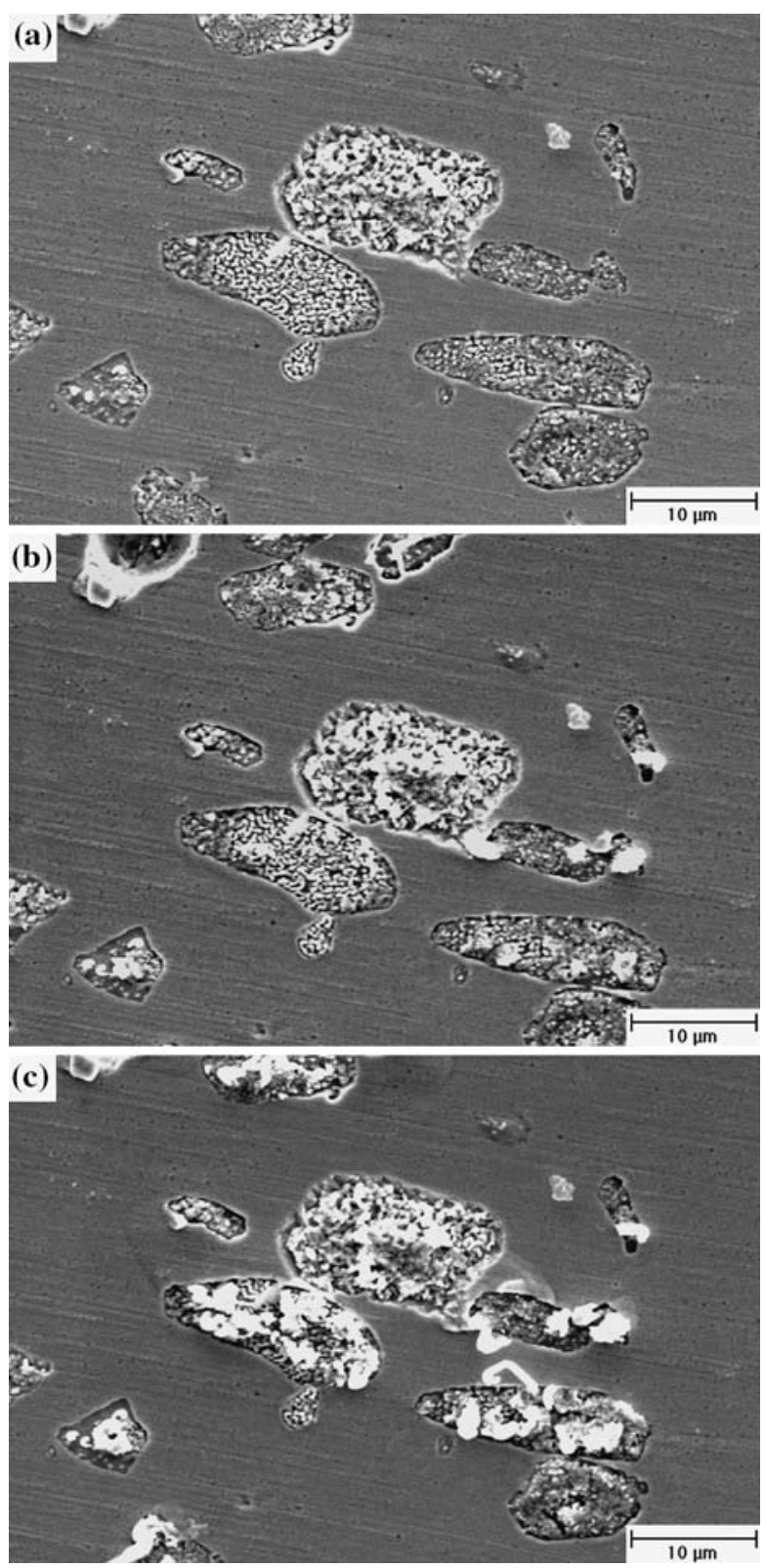

Fig. 2. Tin sprouts on the surfaces of oxidized $\left(\mathrm{La}_{0.93} \mathrm{Ce}_{0.7}\right) \mathrm{Sn}_{3}$ intermetallic clusters in the Sn-6.6(La, Ce) alloy after air storage at room temperature for short periods: (a) $0.5 \mathrm{~h}$, (b) $2 \mathrm{~h}$, and (c) $4 \mathrm{~h}$.

in the $150^{\circ} \mathrm{C}$ air furnace (Fig. 5). It can also be seen in Fig. 5 that fewer tin sprouts appeared in the interior regions of $\left(\mathrm{La}_{0.93} \mathrm{Ce}_{0.07}\right) \mathrm{Sn}_{3}$ intermetallics, and that these had no tendency to lengthen during long-term storage from $40 \mathrm{~h}$ to $224 \mathrm{~h}$ at $150^{\circ} \mathrm{C}$. This failure to lengthen any further indicates that the driving force for the whisker growth was rapidly exhausted in the beginning of the $150^{\circ} \mathrm{C}$ storage period. In comparison to the morphology of $\left(\mathrm{La}_{0.93}\right.$ $\left.\mathrm{Ce}_{0.07}\right) \mathrm{Sn}_{3}$ intermetallics observed on the surface of Sn-6.6(La, Ce) alloy after air storage, both tin whiskers and hillocks were absent when specimens were aged at room temperature and at $150^{\circ} \mathrm{C}$ for $2 \mathrm{~h}$
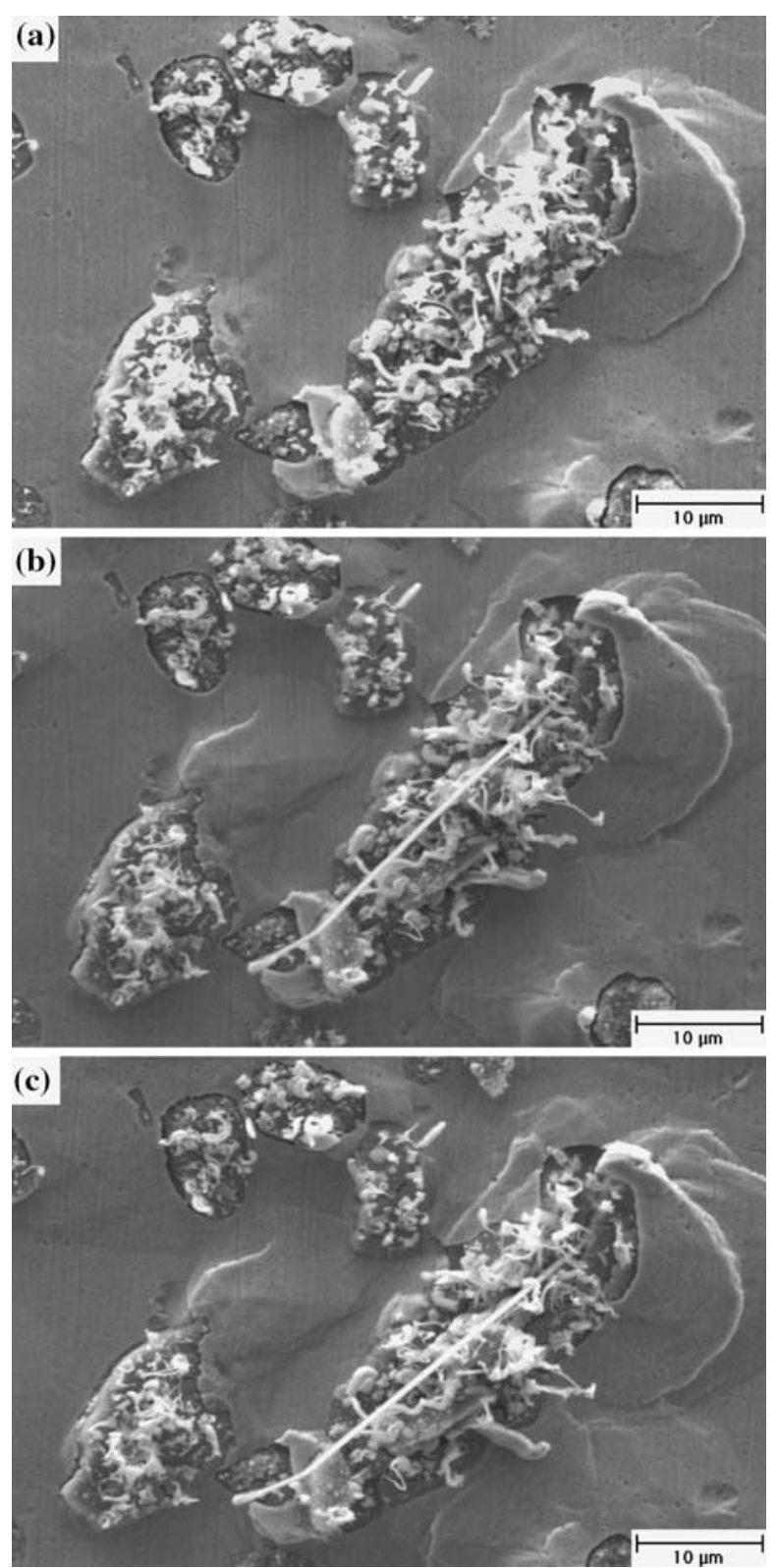

Fig. 3. Tin whisker growth on the surface of oxidized $\left(\mathrm{La}_{0.93}\right.$ $\left.\mathrm{Ce}_{0.7}\right) \mathrm{Sn}_{3}$ intermetallic clusters in $\mathrm{Sn}-6.6(\mathrm{La}, \mathrm{Ce})$ alloy after air storage at room temperature for long periods: (a) $42 \mathrm{~h}$, (b) $188 \mathrm{~h}$, and (c) $559 \mathrm{~h}$.

under $10^{-2}$ Pa vacuum, as illustrated in Fig. $6 \mathrm{a}$ and $\mathrm{b}$, respectively. The results provide evidence that the growth of tin whiskers and hillocks is caused by the oxidation of the $\left(\mathrm{La}_{0.93} \mathrm{Ce}_{0.07}\right) \mathrm{Sn}_{3}$ intermetallic phase. This inference can be reconfirmed by the EPMA analyses of the outer surface of $\left(\mathrm{La}_{0.93}\right.$ $\left.\mathrm{Ce}_{0.07}\right) \mathrm{Sn}_{3}$ clusters during $150^{\circ} \mathrm{C}$ storage in an air furnace for various periods of time. Figure 7 shows that the compositions (at.\%) of La and O increased drastically from 10.2 and 35.8 to 17.1 and 43.6 , respectively, during $150^{\circ} \mathrm{C}$ storage for $30 \mathrm{~min}$. At longer storage times, the compositions of La and $\mathrm{O}$ 

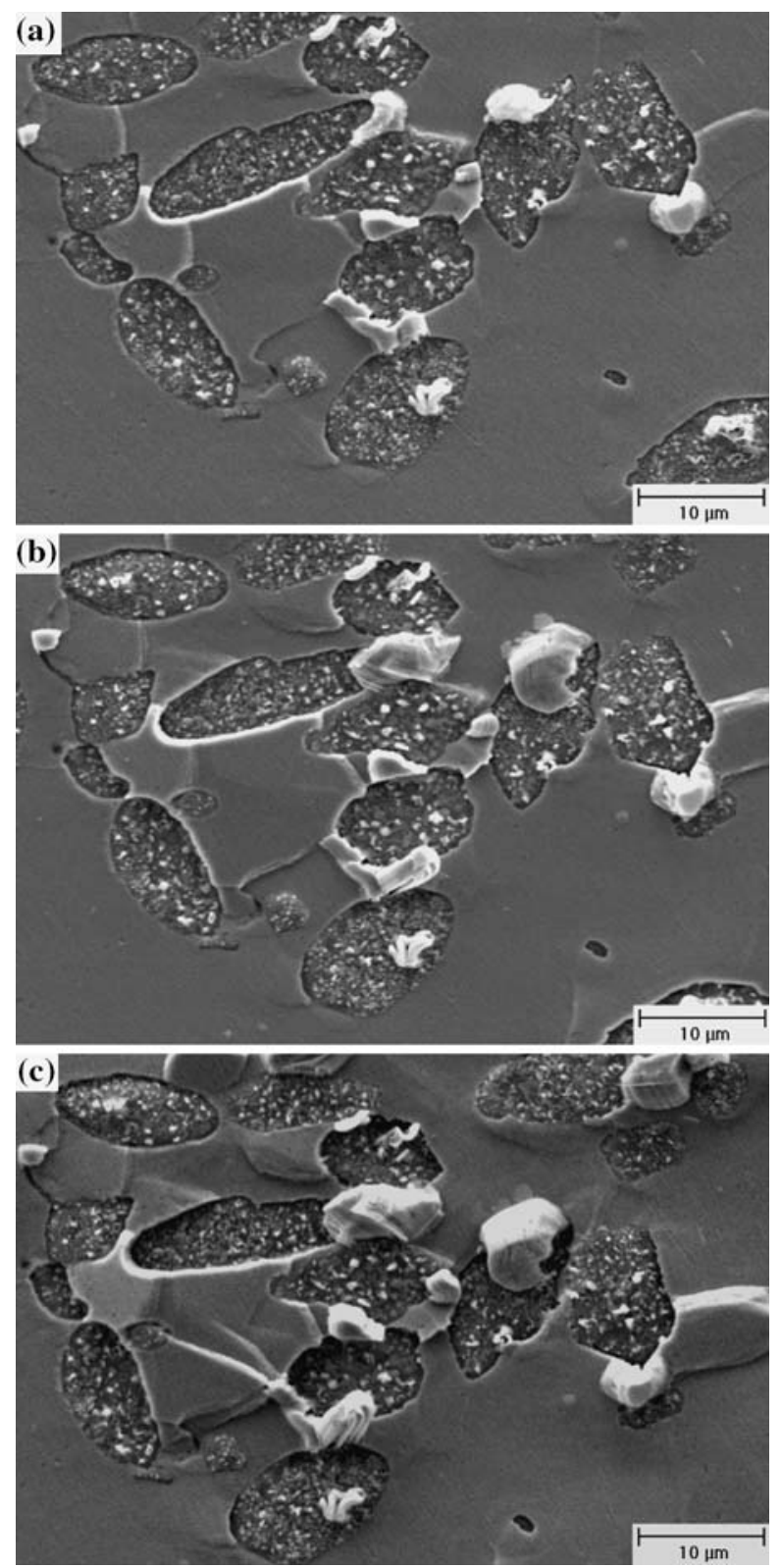

Fig. 4. Hillock formation on the surface of oxidized $\left(\mathrm{La}_{0.93} \mathrm{Ce}_{0.07}\right) \mathrm{Sn}_{3}$ intermetallic clusters in Sn-6.6( $\mathrm{La}, \mathrm{Ce}$ ) alloy after storage at $150^{\circ} \mathrm{C}$ in air furnace for short periods: (a) $10 \mathrm{~min}$, (b) $30 \mathrm{~min}$, and (c) $90 \mathrm{~min}$.

remained almost constant, at 21.5 and 46.7, respectively. In contrast, the composition (at.\%) of Sn decreased from 51.9 to 37.2 in $30 \mathrm{~min}$ and then slowly dropped to 27.9 at $40 \mathrm{~h}$. The composition of Ce increased slightly from 2.1 to 3.9 during $150^{\circ} \mathrm{C}$ storage for $40 \mathrm{~h}$.

The preferential oxidation of $\mathrm{Sn}-6.6(\mathrm{La}, \mathrm{Ce})$ to pure Sn can be evidenced by the TGA curves of the percentage weight gain presented in Fig. 8. It can be seen that, during storage at $150^{\circ} \mathrm{C}$ in air for $100 \mathrm{~min}$, both $\mathrm{Sn}-6.6(\mathrm{La}, \mathrm{Ce})$ and pure $\mathrm{Sn}$ specimens oxidized linearly. However, the Sn-6.6(La, Ce) alloy has an oxidation rate about sixfold higher than
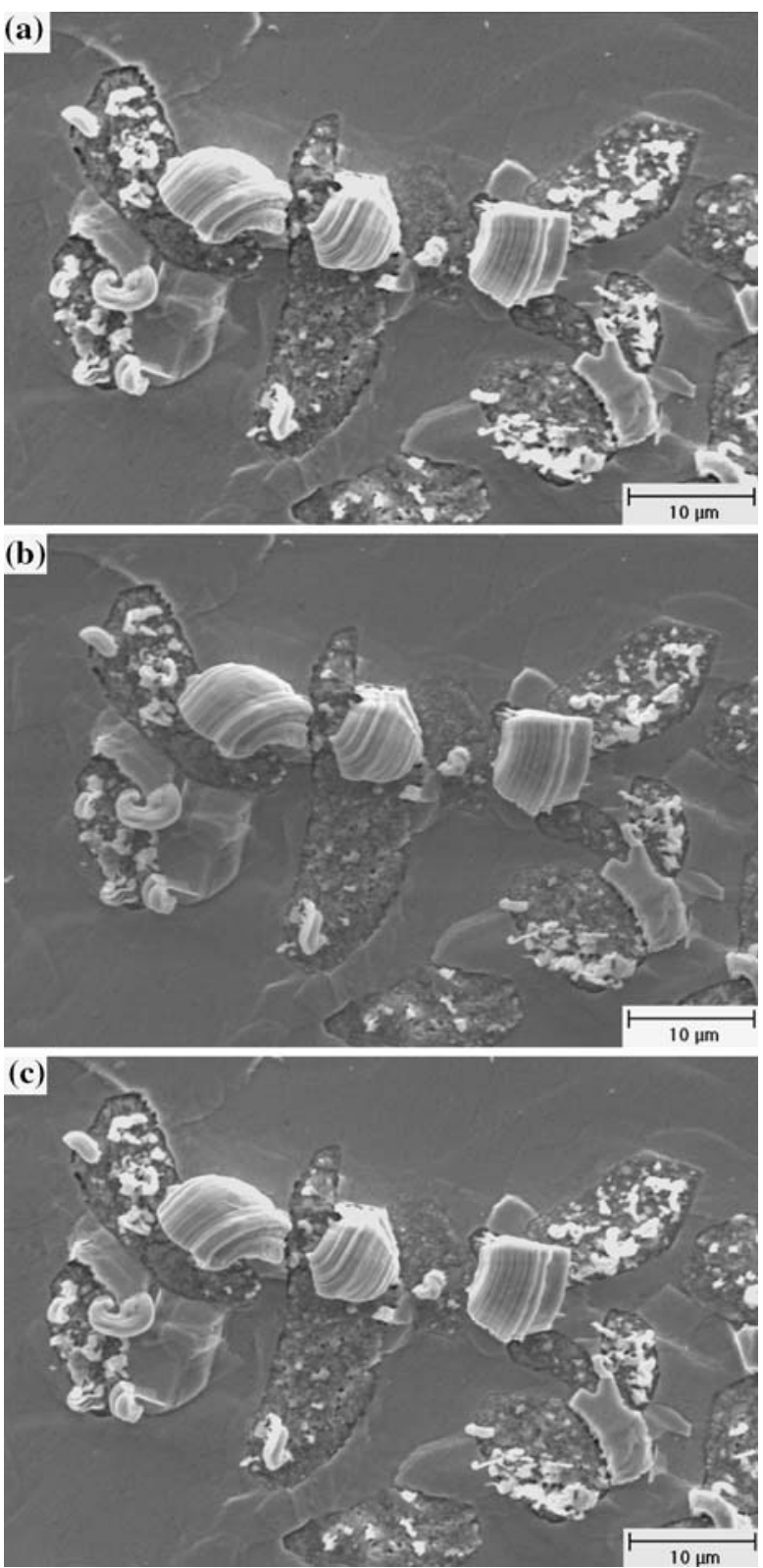

Fig. 5. Hillock formation on the surface of oxidized $\left(\mathrm{La}_{0.93} \mathrm{Ce}_{0.07}\right) \mathrm{Sn}_{3}$ intermetallic clusters in Sn-6.6( $\mathrm{La}, \mathrm{Ce}$ ) alloy after storage at $150^{\circ} \mathrm{C}$ in air furnace for long periods: (a) $40 \mathrm{~h}$, (b) $112 \mathrm{~h}$, and (c) $224 \mathrm{~h}$.

that of pure Sn. Because the La and Ce elements have minor solubility in Sn matrix, the TGA results are attributed to the preferential oxidation of the $\left(\mathrm{La}_{0.93} \mathrm{Ce}_{0.07}\right) \mathrm{Sn}_{3}$ intermetallic phase. The volume expansion of the oxidized $\left(\mathrm{La}_{0.93} \mathrm{Ce}_{0.07}\right) \mathrm{Sn}_{3}$ clusters is constrained by the near $\beta$-Sn matrix, which leads to a compressive stress that causes the Sn atoms around the oxidized $\left(\mathrm{La}_{0.93} \mathrm{Ce}_{0.07}\right) \mathrm{Sn}_{3}$ intermetallic clusters to be extruded out of the specimen surface, thus causing the coarse hillocks shown in Figs. 4 and 5. During air storage at room temperature, Sn-6.6(La, Ce) oxidizes much more slowly than it does at $150^{\circ} \mathrm{C}$, as shown in Fig. 9, which presents 

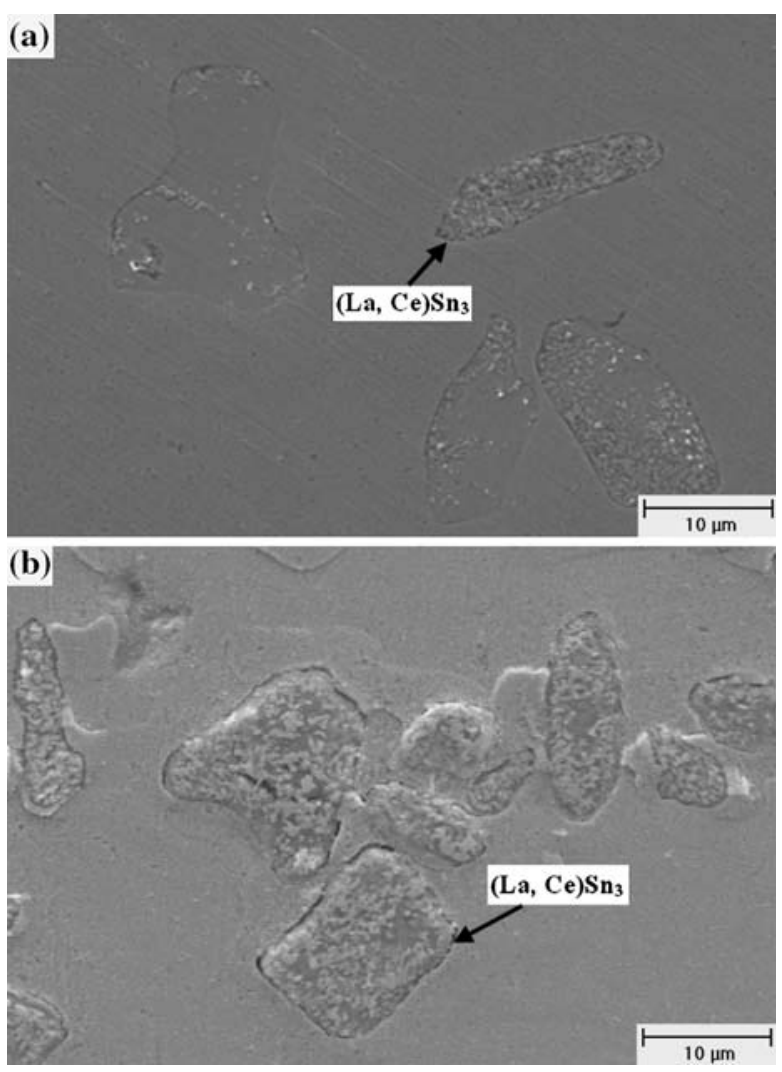

Fig. 6. Morphology of $\left(\mathrm{La}_{0.93} \mathrm{Ce}_{0.07}\right) \mathrm{Sn}_{3}$ intermetallic clusters in $\mathrm{Sn}-6.6(\mathrm{La}, \mathrm{Ce})$ alloy after storage in a vacuum furnace of $10^{-2} \mathrm{~Pa}$ at (a) room temperature for $500 \mathrm{~h}$ and (b) $150^{\circ} \mathrm{C}$ for $2 \mathrm{~h}$.

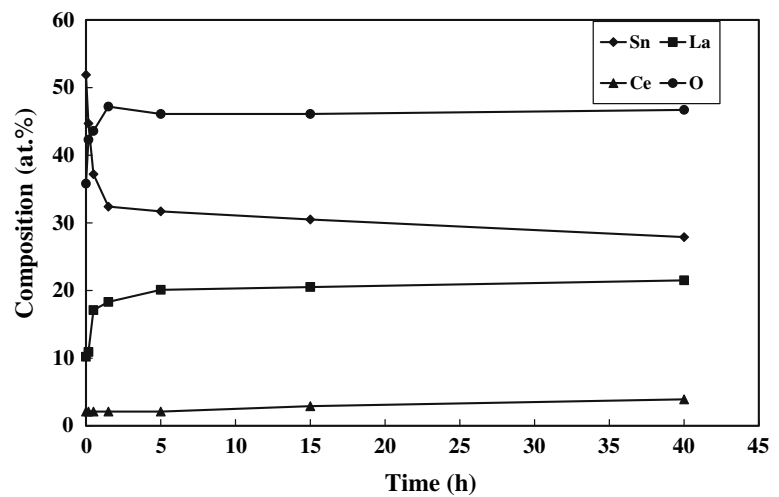

Fig. 7. Composition profile of the outer surface of $\left(\mathrm{La}_{0.93} \mathrm{Ce}_{0.07}\right) \mathrm{Sn}_{3}$ phase formed in Sn-6.6( $\mathrm{La}, \mathrm{Ce})$ specimens stored at $150^{\circ} \mathrm{C}$ in air furnace for various times.

the intermittent measurements of the percentage weight gain of the specimens. In this case, the tin atoms that resulted from the oxidation reaction of $\left(\mathrm{La}_{0.93} \mathrm{Ce}_{0.07}\right) \mathrm{Sn}_{3}$ precipitates were moderately extruded through the weak spots in the oxide layer to form the tin sprouts and whiskers, as shown in Figs. 2 and 3.

In order to further confirm the growth mechanism of tin whiskers and hillocks on the surface of Sn-6.6(La, Ce) alloy, specimens were cut across the

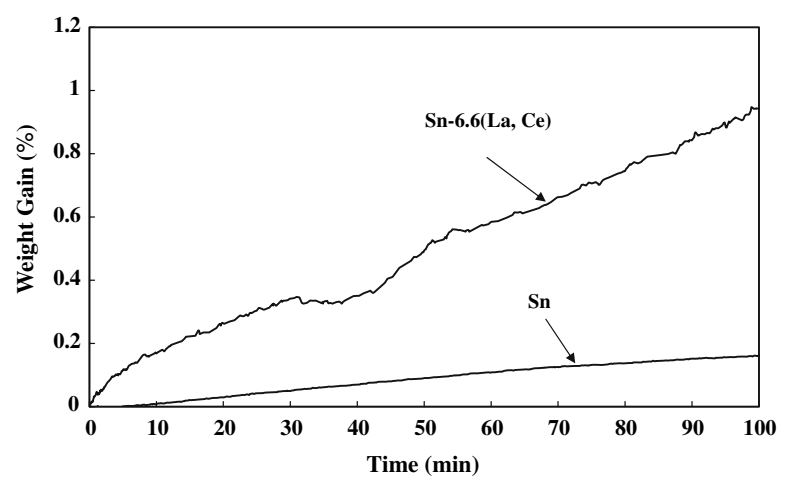

Fig. 8. Percentage weight gain of $\mathrm{Sn}-6.6(\mathrm{La}, \mathrm{Ce})$ alloy and pure $\mathrm{Sn}$ during oxidation reaction at $150^{\circ} \mathrm{C}$ in air.

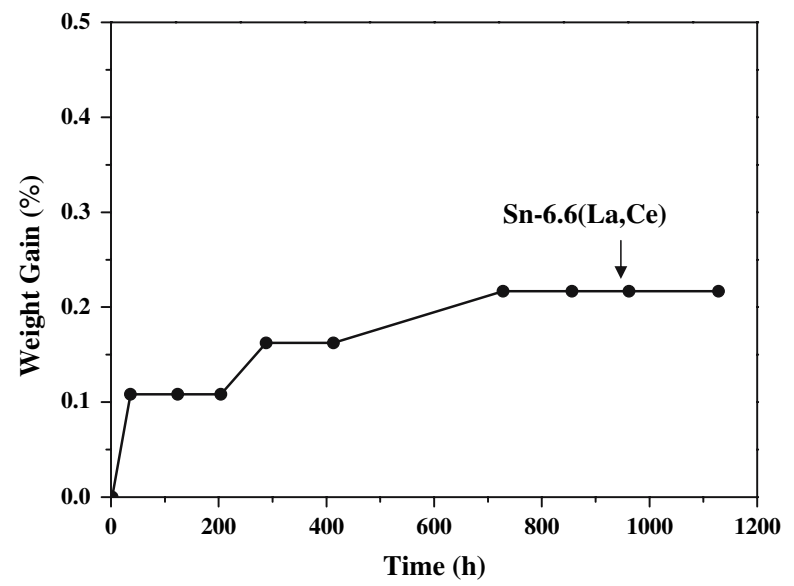

Fig. 9. Percentage weight gain of Sn-6.6(La, Ce) alloy at room temperature.

$\left(\mathrm{La}_{0.93} \mathrm{Ce}_{0.07}\right) \mathrm{Sn}_{3}$ intermetallic clusters, as shown in Fig. 10. It can be seen in Fig. 10a that an oxide layer with cracks appears on the outer surface of the $\left(\mathrm{La}_{0.93} \mathrm{Ce}_{0.07}\right) \mathrm{Sn}_{3}$ intermetallic cluster in a Sn-6.6(La, Ce) specimen stored at room temperature for $48 \mathrm{~h}$. Pure tin atoms released by the $\left(\mathrm{La}_{0.93} \mathrm{Ce}_{0.07}\right) \mathrm{Sn}_{3}$ phase after the oxidation reaction are also found to penetrate through these cracks and sprout out of the oxide layer. However, Fig. 10b shows that a compact oxide layer forms on the $\left(\mathrm{La}_{0.93} \mathrm{Ce}_{0.07}\right) \mathrm{Sn}_{3}$ intermetallics after $150^{\circ} \mathrm{C}$ storage in an air furnace for $1 \mathrm{~h}$. A thin oxide layer can also be observed surrounding the unoxidized rare-earth intermetallic cluster. The absence of cracks, which act as the microchannels to transport the tin atoms after oxidation, explains the lower numbers of tin sprouts and whiskers in the interior regions of the oxide layer on the $\left(\mathrm{La}_{0.93} \mathrm{Ce}_{0.07}\right) \mathrm{Sn}_{3}$ intermetallics, as shown in Figs. 4 and 5. However, the huge compressive stress accumulated by the volume expansion of the compact oxide layer causes coarse hillocks to form around the oxidized $\left(\mathrm{La}_{0.93}\right.$ $\left.\mathrm{Ce}_{0.07}\right) \mathrm{Sn}_{3}$ phase on the surface of the $\mathrm{Sn}-6.6(\mathrm{La}, \mathrm{Ce})$ alloy. 

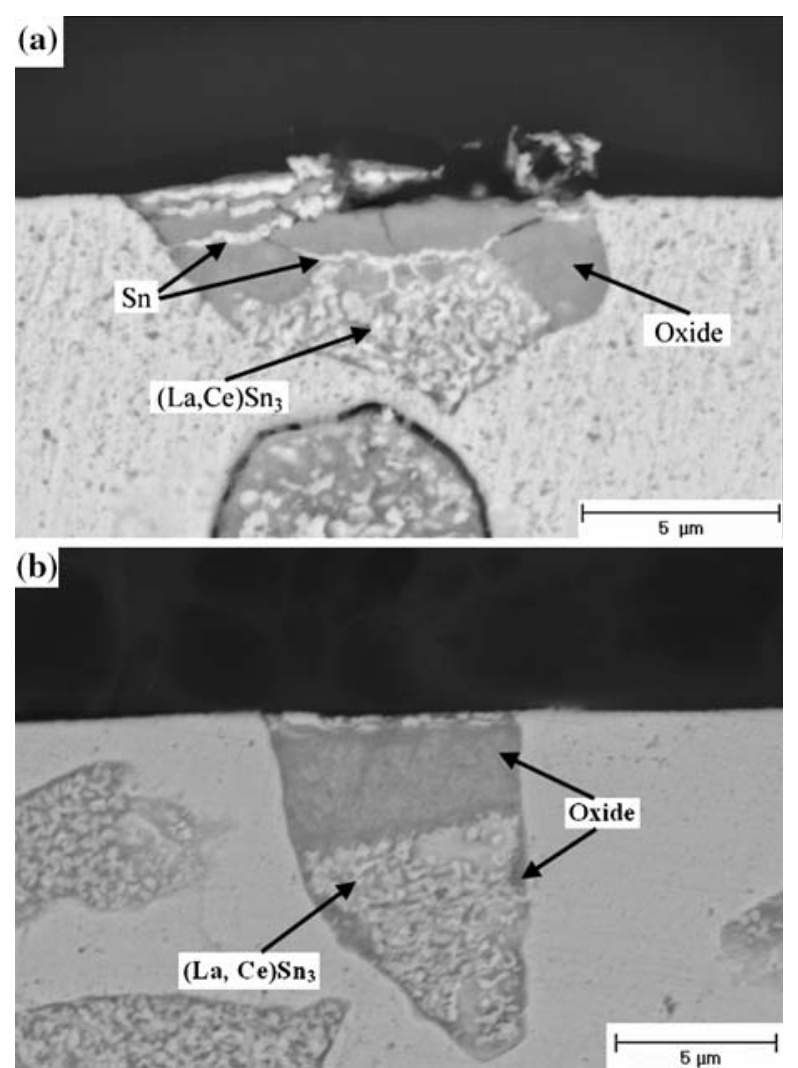

Fig. 10. Cross sections of the oxidized $\left(\mathrm{La}_{0.93} \mathrm{Ce}_{0.07}\right) \mathrm{Sn}_{3}$ intermetallic clusters in Sn-6.6(La, Ce) alloy after air storage at (a) room temperature for $48 \mathrm{~h}$ and (b) $150^{\circ} \mathrm{C}$ for $1 \mathrm{~h}$.

\section{CONCLUSIONS}

After solidification of a Sn-6.6(La, Ce) alloy, many cluster-shaped $\left(\mathrm{La}_{0.93} \mathrm{Ce}_{0.07}\right) \mathrm{Sn}_{3}$ intermetallics with a size of about $10 \mu \mathrm{m}$ can be observed. These peritectic intermetallic clusters oxidize predominately to the $\beta$-Sn matrix during air storage. This oxidation reaction leads to the release of pure Sn atoms. After storage at room temperature, the oxide layer that forms on the $\left(\mathrm{La}_{0.93} \mathrm{Ce}_{0.07}\right) \mathrm{Sn}_{3}$ intermetallics contains cracks that act as microchannels to transport the released Sn atoms out of the specimens, in turn causing the formation of tin sprouts and whiskers in the interior regions of the oxidized rare-earth intermetallics. After storage at $150^{\circ} \mathrm{C}$ in an air furnace, however, a compact oxide layer appears on the $\left(\mathrm{La}_{0.93} \mathrm{Ce}_{0.07}\right) \mathrm{Sn}_{3}$ phase in the $\mathrm{Sn}-6.6(\mathrm{La}, \mathrm{Ce})$ specimens. In addition, a thin oxide layer surrounds the phase clusters. The accumulated compressive stress resulting from the volume expansion of the oxide layer extrudes the nearby Sn-6.6(La, Ce) alloy matrix, causing the formation of many coarse tin hillocks around the $\left(\mathrm{La}_{0.93} \mathrm{Ce}_{0.07}\right) \mathrm{Sn}_{3}$ intermetallic clusters on the surface of this rare-earth-containing alloy.

\section{ACKNOWLEDGEMENTS}

The authors are grateful for the sponsorship of National Science Council, Taiwan, under Grant No. NSC-95-2221-E002-120 and National Taiwan University under Grant No. 95-R210.

\section{REFERENCES}

1. L.Y. Jones, Mat. Sci. Technol. 12, 981 (1996).

2. F. Hillen, D. Pickart-Castillo, Ino J. Rass, and E. Lugscheider, Welding Cutting 52(8), 454 (2000).

3. C.M.L. Wu, D.Q. Yu, C.M.T. Law, and L. Wang, J. Electron. Mater. 31, 921 (2002).

4. C.M.L. Wu, D.Q. Yu, C.M.T. Law, and L. Wang, J. Mater. Res. 17, 3146 (2002).

5. C.M.L. Wu, D.Q. Yu, C.M.T. Law, and L. Wang, J. Electron. Mater. 31, 928 (2002).

6. Z.G. Chen, Y.W. Shi, Z.D. Xia, and Y.F. Yan, J. Electron. Mater. 31, 1122 (2002).

7. M.A. Dudek, R.S. Sidhu, N. Chawla, JOM June, 57 (2006).

8. M.A. Dudek, R.S. Sidhu, N. Chawla, and M. Renavikar, J. Electron. Mater. 35, 2088 (2006).

9. T.H. Chuang and S.F. Yen, J. Electron. Mater. 35, 1621 (2006).

10. T.H. Chuang, S.F. Yen, Mater. Sci. Forum March, 539 (2007).

11. M. Hansen, K. Anderko, eds., Constitution of Binary Alloys (New York, Tornato, London: McGraw-Hill, 1958), p. 892. 